Gut, 1989, 30, 1412-1418

Case reports

\title{
Peculiar acute toxic colitis after ingestion of colocynth: a clinicopathological study of three cases
}

\author{
D GOLDFAIN, A LAVERGNE, A GALIAN, L CHAUVEINC, \\ AND F PRUDHOMME
}

From the Service de Gastroentérologie, Hôpital Victor Jousselin, Dreux, France and Service d'Anatomie Pathologique, Hôpital Lariboisière, Paris, France.

SUMmary We report three examples of toxic acute colitis which occurred after ingestion of colocynth (Citrullus colocynthis) for ritual purposes. The prominent clinical feature was dysenteric diarrhoea; colonoscopic changes included congestion and hyperaemia of the mucosa with abundant exudates but no ulceration or pseudopolyp formation. A causal relationship between colonic injury and the intake of colocynth was supported by the following features: (1) the pharmacology of the colocynth extract ingested; (2) the temporal relationship between colocynth intake and clinical onset (eight to $12 \mathrm{~h}$ ); (3) the rapid recovery within three to six days, with normal endoscopy at day 14; (4) the absence of other possible causes for the observed patterns, except in one case, in which a concomitant intestinal infection with Clostridium perfringens Type A was discovered; (5) the specific pathological features. Colonic biopsies taken 27,44 , and $72 \mathrm{~h}$ after colocynth intake showed: erosions with fibrino-purulent exudate, early fibrosis of the lamina propria, hyaline thickening of the superficial epithelial basal membrane. These pathological features completely disappeared within 14 days in all three cases.

Acute colitis may have many causes: the most frequent are bacteria, parasites and ischaemia but toxic aetiology is rare. Among the cases with this aetiology, we identified an exceptional type of colitis caused by ingestion of a fruit commonly known as colocynth (Citrullus colocynthis). The study of three cases allowed us to report clinical, radiographic and colonoscopy findings and to describe the pathological features of this type of colitis.

\section{Case reports}

Three Moroccan men were admitted to Hospital at Dreux, France respectively in March 1980, December 1982, and January 1983 for acute

Address for correspondence for reprints: Dr A Galian. Service Central d'Anatomic et Cytologie pathologiques. Hopital Lariboisière. 2 rue Ambroise Paré. 75475 Paris Cedex, France.

Accepted for publication 17 February 1989. diarrhoea. They admitted, with great difficulty to having ingested a mixture containing colocynth before the onset of gastrointestinal symptoms; one having done so after one week of hospitalisation. Clinical and biological data are summarised in Table 1.

In the three patients morphological intestinal investigations were performed in the early stages of the disease. Barium enemas (Fig. 1) showed widening of the mucosal folds and lacunar thumbprint images. Colonoscopies (Fig. 2) performed 27 hours (patient 2), 44 hours (patient 3) and 72 hours (patient 1) after colocynth intake disclosed lesions mostly in the sigmoid and descending colonic sections, consisting of thickened oedematous and inflammatory folds with exudates but neither ulceration nor pseudopolyps.

Some early clinical features suggested possible amoebiasis or pseudomembranous colitis. Therefore, 
Table 1

\begin{tabular}{|c|c|c|c|}
\hline Patients & (I) & (2) & (.3) \\
\hline Age (yr) & 51 & 34 & 37 \\
\hline $\begin{array}{l}\text { Significant past medical } \\
\text { history }\end{array}$ & $\begin{array}{l}\text { Ankylosing } \\
\text { spondylarthritis }\end{array}$ & None & None \\
\hline Onset after colocynth ingestion (h) & 12 & 8 & $81 / 2$ \\
\hline \multicolumn{4}{|l|}{ Diarrhoea } \\
\hline Stools $/ 24 \mathrm{~h}$ & $15-20$ & $25-30$ & $20-25$ \\
\hline Containing & Mucus & Blood and mucus & Blood and mucus \\
\hline Physical examination abnormalities & $\begin{array}{l}\text { Diffuse abdominal pain } \\
\text { Deshydration }\end{array}$ & $\begin{array}{l}\text { Diffuse abdominal pain } \\
\text { Deshydration }\end{array}$ & $\begin{array}{l}\text { Left abdominal pain } \\
\text { Deshydration }\end{array}$ \\
\hline Temperature & $38^{\circ} \mathrm{C}$ & $37^{\circ} \mathrm{C}$ & $37^{\circ} \mathrm{C}$ \\
\hline \multicolumn{4}{|l|}{ Routine biology } \\
\hline Blood cell count & $\begin{array}{l}\text { Increased haematocrite } \\
\text { hyperleucocytosis }\end{array}$ & $\begin{array}{l}\text { Increased haematocrite } \\
\text { hyperleucocytosis }\end{array}$ & $\begin{array}{l}\text { Increased haematocrite } \\
\text { hyperleucocytosis }\end{array}$ \\
\hline Blood electrolytes & $\mathrm{N}$ & $\mathrm{N}$ & $\mathrm{N}$ \\
\hline Creatinine & $\mathrm{N}$ & $\mathrm{N}$ & $\mathrm{N}$ \\
\hline Liver tests & $\mathrm{N}$ & $\mathrm{N}$ & $\mathrm{N}$ \\
\hline \multicolumn{4}{|l|}{ Microbiology } \\
\hline Repeated blood cultures & $(-)$ & $(-)$ & $(-)$ \\
\hline $\begin{array}{l}\text { Repeated parasitic stools examinations including the } \\
\text { search of amoebae in fresh specimens }\end{array}$ & $(-)$ & $(-)$ & $(-)$ \\
\hline $\begin{array}{l}\text { Repeated bacteriological stools examinations including } \\
\text { the search of salmonellae shigellae and clostridiae }\end{array}$ & $\begin{array}{l}\text { Clostridium perfringens } \\
\text { Type A }\end{array}$ & $(-)$ & $(-)$ \\
\hline \multicolumn{4}{|c|}{ Immunodiagnostic tests } \\
\hline Amoebiasis & ND & $(-)$ & $(-)$ \\
\hline Schistosomiasis & ND & $(-)$ & ND \\
\hline Cytomegalovirus & ND & $(-)$ & ND \\
\hline Clinical recovery at: & Day 6 & Day 3 & Day 4 \\
\hline
\end{tabular}

N: Normal; (-) Negative; ND: Not done.

after collecting specimens for biological tests and when morphological intestinal investigations were done, patient 1 and patient 3 were given metronidazole $1.5 \mathrm{~g} / 24 \mathrm{~h}$. In the three patients gastrointestinal symptoms completely disappeared within three to six days; a fortnight after colocynth ingestion, colonoscopy revealed normal mucosal pattern (patients 1 and 2) or mild oedematous changes (patient 3 ).

\section{Methods}

PATHOLOGICAL STUDIES

Biopsy specimens were obtained from the rectum and colon, fixed in Bouin's fluid and embedded in paraffin. Three microns thick sections were stained with haematoxylin-eosin-safran, Masson's trichrome and periodic acid Schiff and there were three sections per sample. At least five sequential biopsies were taken from each of the three patients at the following times: the third, seventh and 15th days after ingestion (case 1), the 27th hour, and third and 15th days (case 2 ), and the 44th hour, and 14th and 65th days (case $3)$. Two to 11 colonic biopsies were also obtained from a normal population comprising 20 European controls and 24 Moroccan controls aged from 30 to 50 years, with no symptoms of digestive disease.

\section{Results}

Biopsies appeared normal in 14 European controls and seven Moroccan controls. In the other controls, minor lesions such as a slight hyaline thickening of the superficial epithelial basal membrane were observed combined with mild fibrosis of the lamina propria in three European controls and five Moroccan controls.

In the three patients with colitis, biopsies were studied for different criteria detailed in Table 2. In two patients (patients 1 and 3 ), early lesions consisted of extensive acute erosions, with destruction of the superficial or middle part of the mucosa and a large fibrinous exudate including many leucocytes and very little mucus (Fig. 3a). In the deeper part of the mucosa, crypts were fewer than usual and exhibited cubic cells devoid of mucus (Fig. 3b). No pathogenic agent was seen. The following lesions were observed in all three cases from the 27th hour after colocynth ingestion, and seemed to increase until the seventh day: hyaline thickening of the superficial epithelial basal membrane and discrete fibrosis of the lamina propria, mostly or exclusively located in its superficial area but always independent of the superficial epithelial basal membrane (Fig. 4). This fibrosis was often hyaline, with a few fibroblasts and rare lympho- 


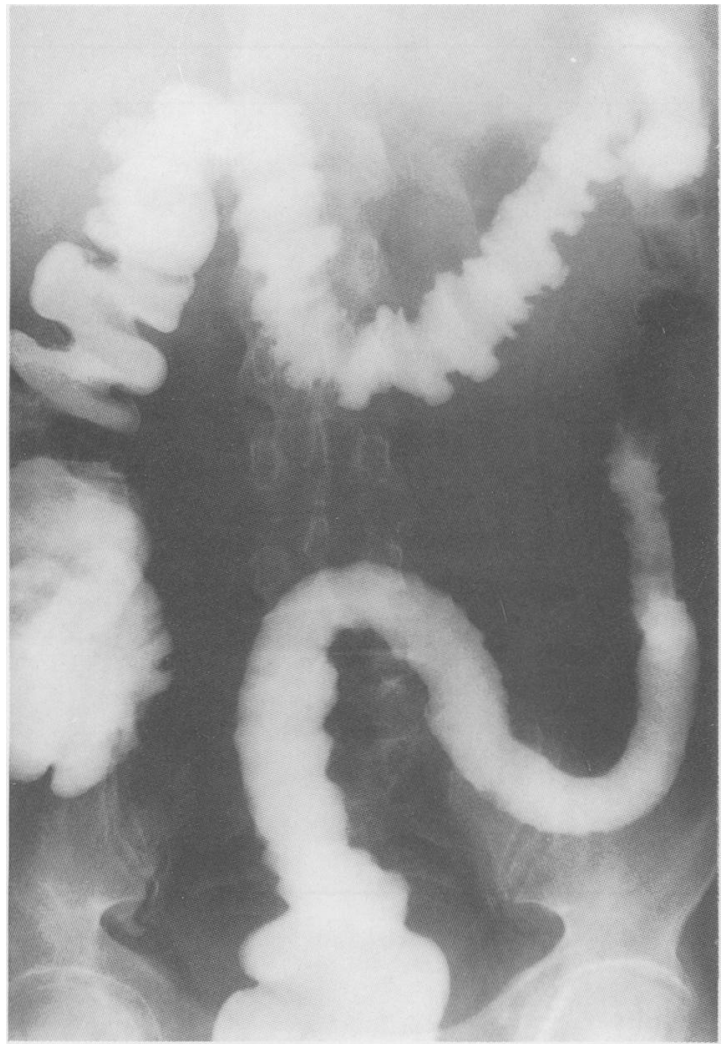

Fig. 1 Patient 2. Barium enema showing disappearance of the normal haustral segmentations and thickening of the mucosal folds.

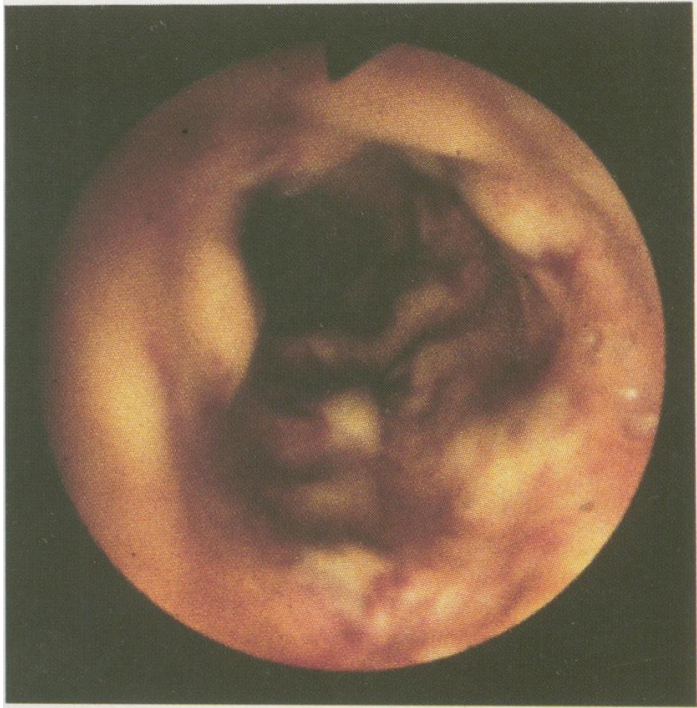

Fig. 2 Patient l. Endoscopic view of the descending colon showing thickening of the folds, inflammatory changes and exudates.

cytes and plasma cells, but almost no polymorphonuclear cells, even under the erosions. Although fibrosis was evident, it was very discrete at the 27 th hour. In all three cases, the number of goblet cells markedly decreased (Fig. 4). The pericryptic basal membrane was normal. The lesions exhibited various degrees of severity in different specimens from the same patient and some specimens were even normal.

Table 2 Details of biopsies

\begin{tabular}{|c|c|c|c|c|c|c|c|c|c|c|}
\hline & & $\begin{array}{l}\text { Early } \\
\text { DI ic }\end{array}$ & & & & & Evolution & DIt & & $J 60$ \\
\hline \multirow{2}{*}{\multicolumn{2}{|c|}{$\begin{array}{l}\text { Patients } \\
\text { Delay of biopsies }\end{array}$}} & \multicolumn{2}{|c|}{ (1) } & \multicolumn{2}{|c|}{ (2) } & \multirow{2}{*}{$\begin{array}{l}(3) \\
\mathrm{H} 44\end{array}$} & \multirow[t]{2}{*}{ (1) } & \multirow[t]{2}{*}{ (2) } & \multirow[t]{2}{*}{ (3) } & \multirow[t]{2}{*}{ (3) } \\
\hline & & D.3 & D7 & $\mathrm{H} 27$ & D3 & & & & & \\
\hline Fen & erosions & ++ & ++ & () & 0 & ++ & () & () & 0 & 0 \\
\hline $\begin{array}{l}\text { Superficiai } \\
\text { epithelium }\end{array}$ & mucous in & $+1-$ & $+1-$ & () & () & $+1-$ & () & 0 & 0 & 0 \\
\hline \multicolumn{2}{|c|}{$\begin{array}{l}\text { Hyaline thickening } \\
\text { of the SEBM }\end{array}$} & ++ & ++ & + & + & + & 0 & $+1-$ & $+1-$ & () \\
\hline \multirow{2}{*}{ Crypts } & Mucosecretion & 1 & 1 & 1 & 1 & 1 & $\mathrm{~N}$ & $\mathrm{~N}$ & $N$ & $N$ \\
\hline & fibrosis & $+1-$ & +++ & $+1-$ & + & + & $+1-0$ & $+1-0$ & 0 & 0 \\
\hline $\begin{array}{l}\text { Lamina } \\
\text { propria }\end{array}$ & $\begin{array}{l}\text { inflammatory } \\
\text { infiltrate }\end{array}$ & $+1-$ & $+1-$ & $+1-0$ & $+/-0$ & $+1-$ & $+1-0$ & $+1-0$ & 0 & () \\
\hline
\end{tabular}

H: hour: D: day: N: normal: 1 : decreased; (): absence: $+/-0$ : slight and inconstant: $+/-:$ slight: + : moderate; $++:$ extensive: $+++:$ very extensive: SEBM: superficial epithelial basal membrane. 

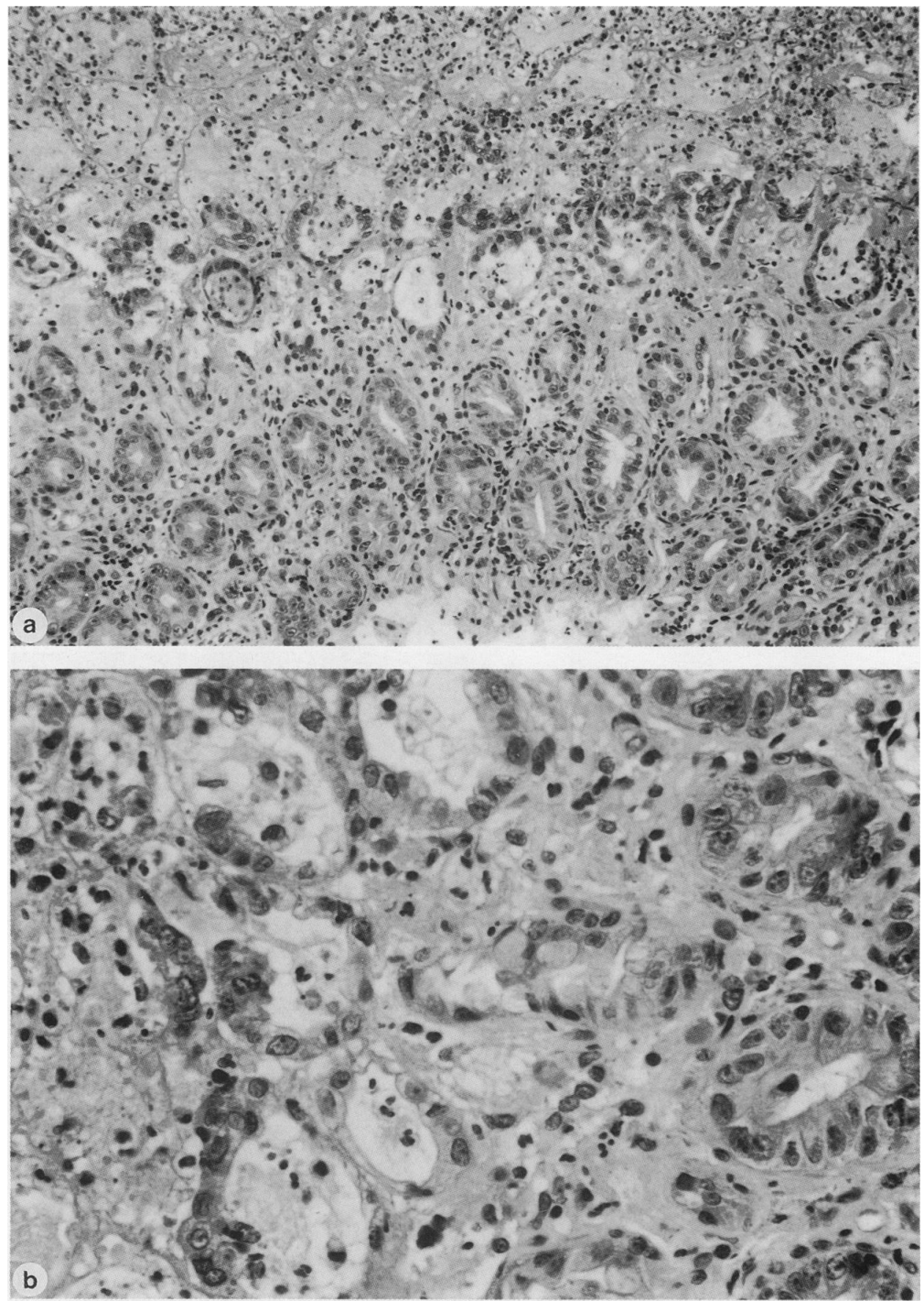

Fig. 3 Patient 3. Colonic biopsy at hour 44 after colocynth ingestion. (a) Extensive acute erosion, with a large fibrinous exudate. Masson's Trichrome. $\times 100$. (b) Extremely rarefied goblet cells in the crypts and rare inflammatory cells in the lamina propria. Hematoxylin-eosin. 


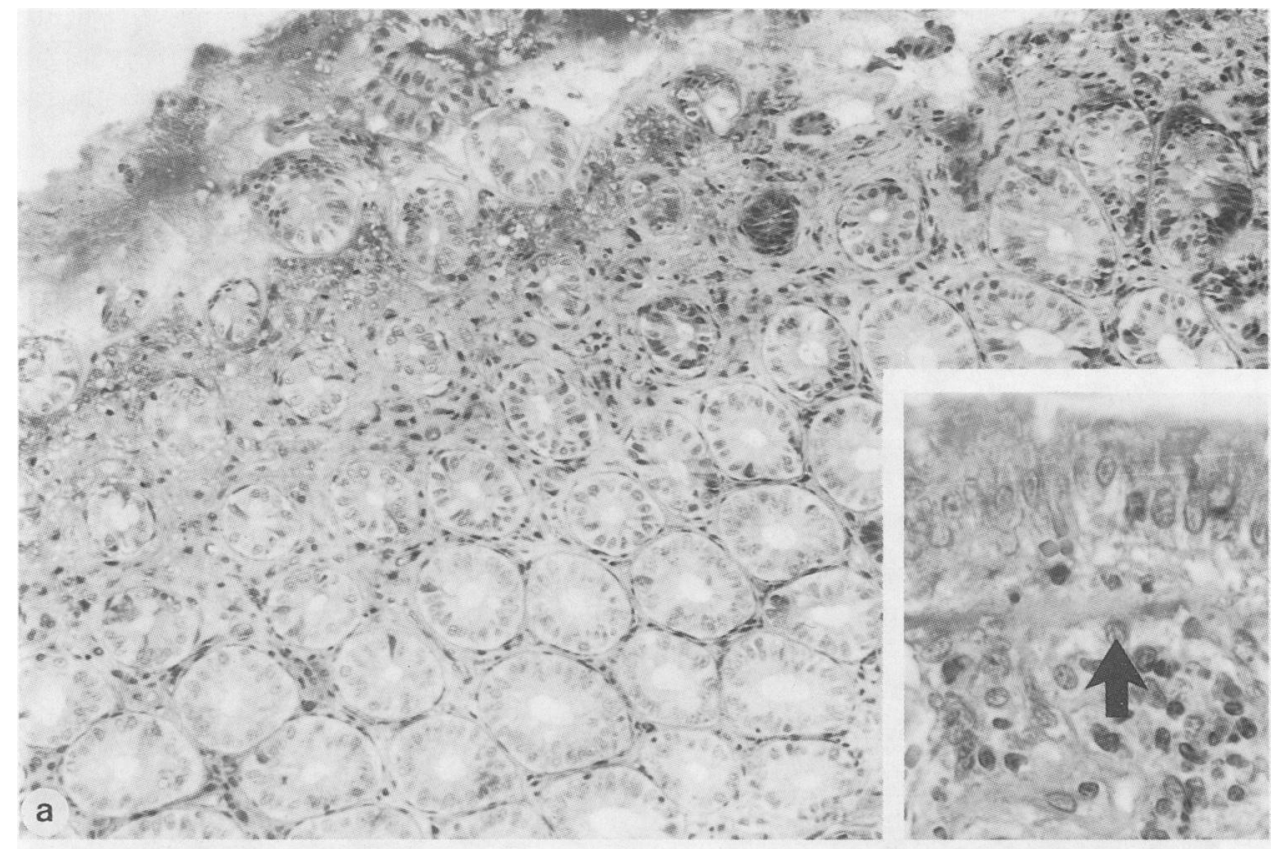

Fig. 4 Patient 2. Colonic biopsy. (a) At hour 27 after colocynth ingestion: discrete fibrosis of the lamina propria and decreased number of goblet cells. Masson's Trichrome. $\times 100$. Inset: hyaline thickening of the superficial epithelial basal membrane (arrow). Masson's Trichrome. $\times 250$. (b) At hour 72: increased extensive fibrosis of the lamina propria. Masson's Trichrome. $\times 100$. 
EVOLUTION OF THE DISEASE

In one patient (case 1), a second series of biopsies were taken on the seventh day after colocynth ingestion. The lesions displayed features similar to those of the first series but the fibrosis of the lamina propria was much more extensive. On the 15 th day, the mucosa had almost returned to normal in the three cases: only very slight thickening of the superficial epithelial basal membrane remained, together with minor fibrosis of the lamina propria, without any special topography. On the 65th day post ingestion, the colonic mucosa was normal in patient 3 , the only one who attended for follow up.

\section{Discussion}

For ritual purposes of purification and vitalisation, the three patients ingested milk introduced into the colocynth, mixed with the pulp and incubated for about 12 hours. According to the patients, this habit is fairly frequent in Morocco, but does not seem usual in other North African countries. This practice may be reminiscent of the use of ritual enemas by certain South African tribes. ${ }^{1}$

The present cases of colitis can be attributed to the ingestion of colocynth for the following reasons: (a) the known pharmacological properties of this fruit $^{2}$; (b) the chronological order of the events (onset of the symptoms within eight to 12 hours after ingestion, fast return to normal within three to six days); (c) the absence of any other cause, and (d) the particular features of the pathological lesions. The colocynth (Citrullus colocynthis), a member of the family of Cucurbitacae, is a drastically strong laxative, known since antiquity; its laxative properties reside in the pulp. 0.6 to $1 \mathrm{~g}$ /day of colocynth extract constitutes an overdose capable of inducing bloody diarrhoea, 2 to $4 \mathrm{~g}$ could be fatal. ${ }^{2}$ In our cases, the amount ingested might have been larger than the habitual amount, hence the clinical manifestations. The faecal presence of type A Clostridium perfringens was shown in one patient. This bacterium is known to induce a common alimentary toxic infection. ${ }^{3}$ The bacterial factor alone, however, can not be incriminated in our case because the histological features were not those of infectious colitis. ${ }^{+}$Only one clinical case of acute colitis as a result of accidental ingestion of colocynth had previously been reported by Berrut et al. ${ }^{5}$ The clinical presentation and colonoscopy findings were very similar to those of our cases, as was the rapidly satisfactory evolution. Histological changes, on a single series of biopsies were similar, but in addition, our cases had the particular characteristic of being combined at an early stage with hyaline thickening of the superficial epithelial basal membrane and fibrosis of the lamina propria; contrary to
Berrut et al we did not observe thrombi in post capillary veinule. In four cases with a long history of ingestion of laxatives including an extract of colocynth," all findings resembled those for laxative colitis. $^{7 \times}$

If admission of colocynth ingestion is not obtained, differential diagnosis, especially with pseudomembranous colitis and chronic ischaemic colitis, can offer some difficulty. Pseudomembranous colitis can be suggested by radiographic and endoscopic findings, and this diagnosis was made by Berrut et al. In fact, it can be excluded in the absence of its usual aetiology (no previous antibiotherapy, lack of Clostridium difficile) and of pathological criteria; as in the case of Berrut et al, our pathological features were not suggestive of pseudomembranous colitis because it necessarily included membranes with mucus; moreover in pseudomembranous colitis the underlying crypts are dilated and full of mucus." In a chronic ischaemic colitis" pathological changes cannot be distinguished from fully developed lesions that occur in our patients - that is, erosions, fibrosis, decreased mucosecretion and hyaline thickening of the superficial epithelial basal membrane. The clinical data, however, and especially the quick complete regression of the abnormalities enabled us to eliminate this diagnosis. Other drug induced colitis can be more easily distinguished." $"$

In our patients, the distinctive character of the changes consisted more particularly of early hyaline thickening of the superficial epithelial basal membrane and slight cellular fibrosis of the lamina propria as soon as the 46th hour after colocynth ingestion, combined with acute inflammatory lesions in two of the three cases. The other points of interest were the multiple erosions covered with a fibrinous leucocyte rich exudate almost devoid of mucus. In addition, the rapid regression of the lesions, especially the superficial epithelial basal membrane thickening; indicates the truly pathological character of these findings. The mechanism inducing the rapid onset and disappearance of these characteristic lesions, however, is not clear.

A part of this study has been previously published in abstract form (Gastroenterol Clin Biol 1987; 11: 27)

\section{References}

1 Segal I, Ou Tim L, Hamilton DG, et al. Ritual-enemainduced colitis. Dis Colon Rectum 1979; 22: 195-9.

2 Soulier H. Traité de thérapeutique et de pharmacologie, Tome II.F. Paris: Savy, 1891: 394-5.

3 Plotkin GR, Kluge RM, Waldmann RH. Gastroenteritis: etiology, pathophysiology and clinical manifestations. Medicine (Baltimore) 1979; 58: 95-114. 
4 Kumar NW, Nostrant TT, Appelman HD. The histopathologic spectrum of acute self limited colitis (acute infectious type colitis). Am J Surg Pathol 1982; 6: 523-9.

5 Berrut C, Bisetti A, Widgren S, Tissot JD, Loizeau E. Colite pseudomembraneuse causéc par l'ingestion de coloquinte. Schweiz Med Wochenschr 1987: 117: $135-8$.

6 Rawson MD, Leeds MB. Cathartic colon. Lancet 1966; i: $1121-4$.

7 Cooke WT. Laxative abuse. Clin Gastroenterol 1977; 6: 659-73.
8 Morson BC. Histopathology of cathartic colon. (jut 1971: 12: 867-8.

9 Price AB. Davies DR. Pseudomembranous colitis. $J$ Clin Pathol 1977: 30: 1-12.

10 Marston A. Murray TP. Lea Thomas M. Morson BC. Ischacmic colitis. Gut 1966; 7: 1-15.

11 Meisel JL. Bergman D. Grancy D. Saunders DR, Rubin CE. Human rectal mucosa: proctoscopic and morphologic changes caused by laxatives Gastroenterology 1977: 72: 1274-9.

12 Fortson WC, Tedesco FJ. Drug-induced colitis: a review. Am J Gastroenterol 1984; 79: 878-83. 